\title{
Dois enfoques conceituais para a pesquisa científica sobre sistemas locais de sementes
}

\section{Two conceptual approaches for the scientific investigation on farmers' local seed systems}

\author{
Gabriel Bianconi Fernandes \\ Programa de Pós-Graduação em História das Ciências e das Técnicas e Epistemologia \\ (HCTE), Universidade Federal do Rio de Janeiro (UFRJ). \\ biefernandes@gmail.com \\ orcid.org/0000-0002-1135-7414
}

\section{José Carlos de Oliveira}

Programa de Pós-Graduação em História das Ciências e das Técnicas e Epistemologia (HCTE), Universidade Federal do Rio de Janeiro (UFRJ).

jcarlos@dee.ufrj.br

orcid.org/0000-0002-0415-4926

Resumo. O conhecimento que os agricultores familiares aplicam em suas práticas de conservação, seleção e uso de sementes crioulas é muitas vezes tido pela ciência agrícola institucionalizada como atrasado, embora sejam, ao mesmo tempo, saberes responsáveis pela conservação de recursos genéticos centrais para a garantia da segurança alimentar e desenvolvidos no contexto de sistemas agrícolas mais resilientes aos efeitos das mudanças climáticas. Omesmo conhecimento que pode ser negado em suas credenciais epistêmicas pode ser valorizado enquanto fonte de prospecção de genes de interesse da indústria e de matéria prima para o desenvolvimento de sementes comerciais. A ecologia de saberes de Boaventura de Souza Santos e o pluralismo metodológico de Hugh Lacey são usados comparativamente para se discutir essa contradição. São apresentadas estratégias de pesquisa que permitem investigar a fecundidade do conhecimento tradicional incorporado nas sementes crioulas.

Palavras-chave: Pesquisa em agroecologia. Conhecimento tradicional. Ecologia de saberes. Pluralismo metodológico. 


\begin{abstract}
Family farmers' knowledge applied in local seeds management practices is often disregarded by institutional agricultural science, although they keep playing a central role in the conservation of genetic resources key for food security which are developed in the context of agricultural systems more resilient to the effects of climate change. The same knowledge that can be overlooked in their epistemic credentials can be valued as important sources for gene prospection of interest to the industry and as raw materials for the development of commercial seeds. The ecology of knowledge of Boaventura de Souza Santos and the methodological pluralism proposed by Hugh Lacey are used comparatively to discuss such contradiction. Research strategies are presented to investigate the soundness of traditional knowledge embedded in traditional seed varieties.
\end{abstract}

Keywords: Agroecological research. Traditional knowledge. Ecology of knowledges. Methodological pluralism.

Recebido: 01/10/2018 Aceito: 27/10/2018 Publicado: 05/11/2018

\title{
1. Introdução
}

As sementes melhoradas comercialmente são promovidas como as únicas válidas para alcançar uma agricultura produtiva e competitiva pois são produto direto da pesquisa científica institucional. Por outro lado, milhões de agricultores pelo mundo cultivam suas próprias sementes, que são por eles selecionadas a partir de critérios próprios que atendem às demandas locais e conservadas há gerações. Essas sementes, chamadas de crioulas, locais, tradicionais, da paixão, da resistência, entre outros, compõem a agrobiodiversidade e a base genética da nossa alimentação (FERNANDES, 2017). Por outro lado, essas sementes são também fonte de matéria prima para pesquisadores e empresas desenvolverem variedades melhoradas, entre elas sementes transgênicas. Nessa condição de matéria prima para variedades patenteadas ou protegidas por direitos de melhoristas, as sementes crioulas são aceitas pela mesma pesquisa científica que as nega enquanto sementes quando nas mãos dos agricultores. Este artigo apoia-se nas teorias do pensamento pós-abissal, proposto pelo sociólogo Boaventura de Sousa Santos, e da pluralidade metodológica, formulada pelo filósofo da ciência Hugh Lacey, para explorar essa contradição no interior da pesquisa científica no que diz respeito à fecundidade do conhecimento tradicional associado às sementes crioulas.

\section{O conhecimento que as sementes crioulas incorporam}

As sementes crioulas são usadas e conservadas pelos agricultores por responderem às suas diferentes necessidades alimentares e produtivas e por serem adaptadas a seus sistemas de produção, tanto do ponto de vista das condições ambientais da região onde se encontram, como do ponto de vista do manejo, principalmente pela baixa 
dependência de insumos externos(BELLON, 1991). Essa maior adaptação, por sua vez, é fruto da seleção intencionalmente feita pelos agricultores (PERALES; BRUSH; QUALSET, 2003) e de conhecimento bastante específico quanto ao local (LACEY, 2000). Ou seja, um dos objetivos da seleção (genética) e do melhoramento feito pelas famílias agricultoras é adaptar as sementes cultivadas a seus (agroeco)sistemas e clima. Os critérios de seleção aplicados visam manter uma diversidade que responde tanto aos critérios alimentares (gosto, preferência etc.) como aos critérios produtivos e de comercialização(FERNANDES et al., 2019). Estudos evidenciam que é exatamente em função de suas múltiplas funções no âmbito das estratégias de vida dos agricultores que o paradigma das sementes crioulas existiu e tudo indica que continuará existindo, ainda que com a condição de informal, local, menos produtivo e não-científico (JARVIS et al., 2011).

\section{A linha abissal que separa as sementes}

Boaventura de Sousa Santos (SANTOS, 2007) aponta a existência de uma injustiça cognitiva, que separa o mundo em dois, um com conhecimentos válidos ("o lado de cá") e outro que é por este ativamente negado e desacreditado ("o lado de lá"). Santos argumenta que se no período colonial uma linha cartográfica abissal separava o Velho Mundo do Novo Mundo, essa linha hoje subsiste estruturalmente no pensamento moderno ocidental e permanece constitutiva das relações políticas e culturais excludentes mantidas no mundo contemporâneo. Tudo o que fica do lado de lá é parte do mecanismo intencional de produção de inexistência(SANTOS, 2007). Não há possibilidade de coexistência entre os dois lados da linha.

No campo do conhecimento, o pensamento abissal concede à ciência o monopólio da distinção entre falso e verdadeiro. A visibilidade dessa forma de verdade científica assenta-se na invisibilidade de outras formas de conhecimento: conhecimentos populares, camponeses ou indígenas estão do outro lado da linha e desaparecem como conhecimentos relevantes ou comensuráveis por se encontrarem para além do universo do verdadeiro e do falso. Mas se o conhecimento que os agricultores aplicam em suas práticas de conservação, seleção e uso de sementes é responsável pela conservação dos recursos genéticos para a alimentação, pela promoção da segurança alimentar e por agroecossistemas mais resilientes, por que ele é muitas vezes tido como atrasado ou mesmo negado? Esse monopólio do conhecimento válido está no cerne da disputa epistemológica moderna entre as formas de verdade científicas e não-científicas. $O$ presente que vai sendo criado do outro lado da linha é tornado invisível e ao ser reconceitualizado como o passado irreversível deste lado da linha, isto é: plantar sementes crioulas é coisa do passado. A esse modelo de racionalidade Santos dá o nome de razão indolente, que manifesta-se, entre outras formas, no modo como se resiste à mudança das rotinas e na forma como se transforma interesses hegemônicos em conhecimentos verdadeiros (SANTOS, 2002). 
O pensamento pós-abissal que pode ser atingido por meio da ecologia de saberes se baseia na ideia de que o conhecimento é interconhecimento e que todas as formas de conhecimento são, de diferentes maneiras, incompletas. Assim, a primeira condição para um pensamento pós-abissal é a co-presença radical, que significa que práticas e agentes de ambos os lados da linha são contemporâneos em termos igualitários. Significa reconhecer que todos os conhecimentos sustentam práticas e constituem sujeitos e, sendo assim, reconhecer a validade do conhecimento embutido nas sementes crioulas e nas práticas de produção, seleção e uso que garantem sua conservação. Significa reconhecer a validade do conhecimento dos sujeitos que conservam essas sementes.

$\mathrm{Na}$ ecologia de saberes, a busca de credibilidade para os conhecimentos não-científicos não implica o descrédito do conhecimento científico, implica simplesmente na sua utilização contra-hegemônica. Trata-se de explorar a pluralidade interna da ciência e de superar a incomensurabilidade que a linha abissal impõe entre seus dois lados. Uma das premissas básicas da ecologia de saberes é que todos os conhecimentos têm limites internos, referentes às intervenções no real que eles permitem, e externo, decorrentes do reconhecimento de intervenções alternativas propiciadas por outras formas de conhecimento. A visibilidade dessa forma de verdade científica assenta-se na invisibilidade de formas de conhecimento que não se encaixam em nenhuma dessas modalidades (conhecimentos populares, camponeses ou indígenas do outro lado da linha) que desaparecem como conhecimentos relevantes ou comensuráveis por se encontrarem para além do universo do verdadeiro e do falso. É nesse sentido que argumentamos pela ecologia de saberes no caso das sementes, e que esse tipo de investigação deve se dar no âmbito de projetos de pesquisa em Agroecologia.

\section{Valores e a pesquisa científica sobre sementes}

Se para Boaventura Santos, os conhecimentos informados não exclusivamente pela pesquisa científica são negados enquanto alternativas existentes e viáveis pois estão do lado de lá da linha abissal, para Hugh Lacey essa negação vem do fato de eles não responderem a estratégias descontextualizadas de pesquisa e que visam interesses comerciais. Para Lacey, a Agroecologia não é tida como alternativa (por ex. aos riscos dos transgênicos, cf. (por ex. aos riscos dos transgênicos, cf. FERMENT et al., 2015) pois não se encaixa nas estratégias de pesquisa que visam gerar produtos da tecnociência e não o bem-estar social para todos e em todos os lugares e a justiça social (LACEY, 2000). A negação de seu status científico vem também do fato de a Agroecologia e, dentro disso, as sementes crioulas, terem como perspectiva a soberania e a segurança alimentar.

Lacey é crítico dos enfoques que limitam as discussões sobre a responsabilidade dos cientistas aos usos e aos efeitos das técnicas ou das inovações geradas. Ou seja, considerando as tendências de aproximação da ciência à tecnociência e o crescimento da ciência no interesse privado, o autor pergunta se a prática (conduta) da ciência está hoje 
a serviço de poderosos interesses privados ou se é pautada pelo respeito à natureza, pelo bem-estar humano universal e por valores democráticos (LACEY, 2008). Daí sua ênfase na importância de se discutir a conduta da pesquisa científica. Além disso, questiona a legitimidade da pesquisa científica voltada para a inovação tecnocientífica uma vez que essas não contemplam os estudos sobre riscos e alternativas(LACEY, 2017).

Objetividade, Neutralidade e Autonomia na pesquisa científica são valores defendidos por Lacey cujo atendimento ideal serve para contrabalançar as distorções das práticas científicas subordinadas a interesses [e valores] comerciais e políticos. Eles podem ser resumidos da seguinte forma(LACEY, 2006):

Objetividade (imparcialidade): somente dados empíricos e critérios cognitivos (epistêmicos) apropriados devem ser relevantes para avaliar a confirmação de teorias e hipóteses científicas. Esses critérios não permitem papel para os valores éticos e sociais ou os interesses dos poderosos;

Neutralidade: valores e juízos éticos não podem ser inferidos de resultados científicos confirmados. Esses resultados (na sua totalidade) devem servir equitativamente a projetos que manifestam perspectivas éticas viáveis, e não só aquelas do capital do mercado (ou do financiador da pesquisa). Juízos éticos não podem ser logicamente inferidos (ou implicados) a partir dos resultados científicos; e

Autonomia: decisões acerca da metodologia não deve refletir perspectivas éticas particulares nem valores particulares; as instituições não devem ser sobrecarregadas com interesses extra-científicos.

O modelo de interação entre pesquisa e valores proposto por Lacey aponta para um pluralismo metodológico (consistente com o diálogo da Ecologia de Saberes proposta por Boaventura Santos). Não se trata de negar o papel e a contribuição das pesquisas descontextualizadas, mas entender que elas sim podem trazer aportes para a pesquisa em Agroecologia. Desde que a utilidade dos resultados obtidos a partir de estratégias descontextualizadas de pesquisa não sirvam exclusivamente a um determinado campo, identifica-se aqui possibilidade de diálogo entre a neutralidade como ideal da prática científica e o pluralismo metodológico visando estratégias de pesquisa que respeitem a natureza e promovam o bem-estar humano.

\section{Hipóteses para a pesquisa sobre sementes crioulas}

As perspectivas críticas que Santos e Lacey apresentam à ciência hegemônica e às práticas que a produz como único conhecimento válido - negando quaisquer formas e fontes alternativas de produção de conhecimentos - foram aqui trabalhadas no sentido de dar origem a algumas hipóteses para pesquisa sobre sementes crioulas:

(i) As famílias agricultoras, os povos indígenas e as comunidades tradicionais selecionam suas sementes tanto para manter as características desejadas como para aumentar a diversidade das variedades que cultivadas; 
(ii) As variedades locais possuem características específicas que respondem a diferentes objetivos dos sistemas produtivos e por isso são até hoje mantidas e cultivadas pelos agricultores familiares, povos indígenas e comunidades tradicionais;

(iii) Essas comunidades possuem mecanismos próprios de promover a circulação e o acesso a sementes e estes contribuem para a conservação dessas espécies e para sua evolução recente;

Essas hipóteses podem ser desagregadas em algumas perguntas de pesquisa:

(i) Por que os agricultores continuam mantendo suas variedades mesmo na presença de oferta de variedades modernas?

(ii) Como assementes crioulas são mantidas e manejadas; quais os mecanismos individuais e comunitários responsáveis por sua conservação?

(iii) Quais princípios ecológicos estão presentes na conservação das sementes crioulas realizada pelos agricultores familiares?

Do ponto de vista da operacionalização dessa estratégia, o desafio é rever, em alguma medida, teórica e empiricamente, alguns pressupostos da ciência moderna, buscando identificar brechas que permitirão estabelecer pontes para sua abertura para uma visão e uma prática pluralista. Isso significa incorporar as estratégias, os conhecimentos e as visões de mundo constitutivas dos sistemas agrícolas tradicionais. Isso não significa fechar os sistemas tradicionais, os recursos e os conhecimentos sobre a biodiversidade nativa e cultivada, para a pesquisa (até porque esses sistemas nunca foram fechados), significa que o processo deve se dar em condições mais justas e equitativas(GREEN, 2008). "A busca de credibilidade para os conhecimentos não científicos não implica o descrédito do conhecimento científico, implica simplesmente na sua utilização contrahegemônica" (SANTOS, 2007). Para que isso aconteça, é necessário que o abismo entre os status dos diferentes conhecimentos seja revisto. E se isso acontecer, se a ciência moderna perder seu status de única forma de conhecimento válido, isso não implica invalidação da ciência como um todo, mas sim a criação de espaço para outros sistemas de produção de conhecimento (KLOPPENBURG, 1991).

Os valores cognitivos centrais da investigação agroecológica, precisamente porque se trata de uma estratégia de investigação contextualizada, têm em conta o conhecimento local dos agricultores (Figura 1). Estas características acreditam-no para explorar áreas de conhecimento intencionalmente descobertas ou metodologicamente inatingíveis através de estratégias de investigação descontextualizadas(FERNANDES, 2020). 


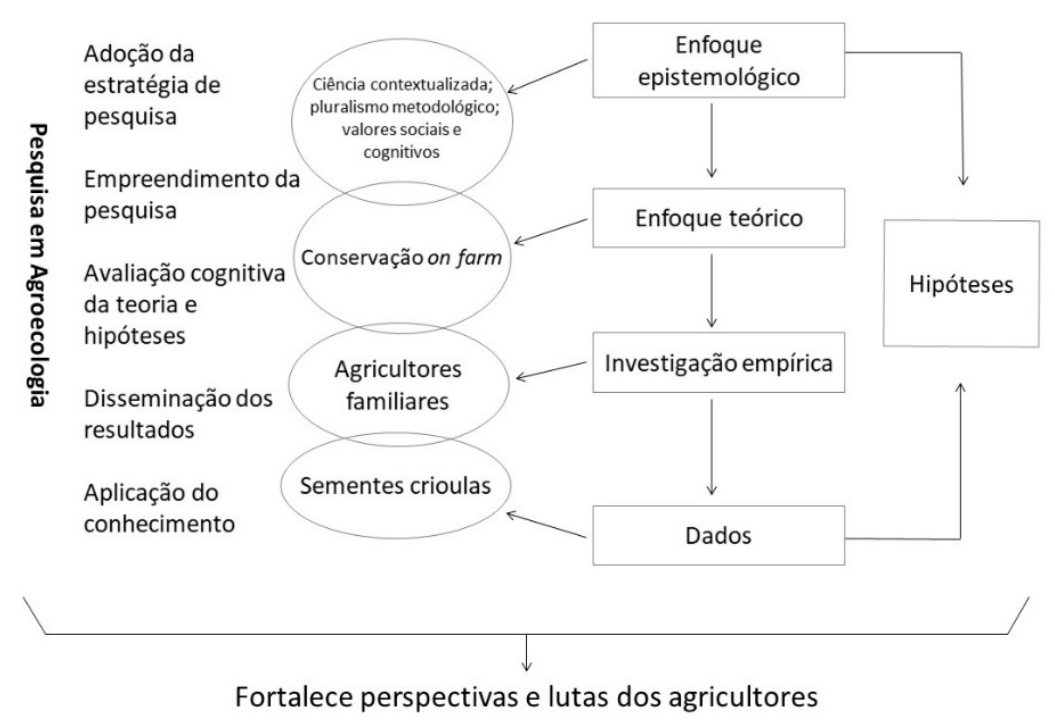

Figura 1. Estratégia plural de pesquisa.

Fonte: Elaborado pelos autores a partir de Lacey e Mariconda (2014).

\section{Conclusões}

A pesquisa em Agroecologia, assim como acontece em outras estratégias de investigação científica, é constituída por valores cognitivos articulados a valores sociais. Valores sociais não associados ao controle da Natureza ou ao progresso material não diminuem a capacidade de uma dada estratégia de pesquisa gerar conhecimentos que ampliem a compreensão de um dado fenómeno e as suas ligações com o ambiente de que faz parte. Isso significa dizer que a pesquisa em Agroecologia pode ser tão ou mais frutífera que qualquer outra estratégia de investigação. O conjunto de valores sociais associados à Agroecologia enquanto enfoque científico são aqueles comprometidos com a sustentabilidade, a soberania alimentar, a justiça social e o fortalecimento dos atores e organizações locais. Estes valores diferem daqueles que orientam a abordagem dominante da pesquisa agrícola institucionalizada. Outra característica da pesquisa em Agroecologia é o fato de esta não excluir, por princípio, a utilização de estratégias descontextualizadas, mas também não se limitar a elas. A pesquisa em Agroecologia leva em consideração o contexto em que os objetos e fenômenos de estudo e seus atores sociais estão imersos.

\section{Financiamento}

O presente trabalho foi realizado com apoio da Coordenação de Aperfeiçoamento de Pessoal de Nível Superior - Brasil (CAPES) - Código de Financiamento 001.

\section{Referências}


BELLON, M. R. The Ethnoecology of Maize Variety Management: A Case Study from Mexico. Human Ecology, v. 19, n. 3, p. 389-418, set. 1991.

FERMENT, G. et al. Lavouras transgênicas: riscos e incertezas: mais de $\mathbf{7 5 0}$ estudos desprezados pelos órgãos reguladores de OGMs. Brasília: Ministério do Desenvolvimento Agrário, 2015.

FERNANDES, G. B. Sementes crioulas, orgânicas e varietais para a agricultura familiar: da exceção legal à política pública. In: SAMBUICHI, R. H. R. et al. (Ed.). A Política nacional de agroecologia e produção orgânica no Brasil: uma trajetória de luta pelo desenvolvimento rural sustentável. Brasília, DF: Ipea, 2017. p. 327-357.

FERNANDES, G. B. et al. A "Dinâmica Das Espigas": Como os agricultores da Zona da Mata de Minas Gerais, Brasil, selecionam suas Sementes e ampliam a diversidade do milho? In: Memorias del VII Congreso Latinoamericano de Agroecología. Guayaquil, Equador: Socla, 2019. p. 35-41.

FERNANDES, G. B. Pesquisa em Agroecologia: reflexões a partir do estudo de sistemas locais de conservação e uso de sementes crioulas. 2020. Universidade Federal do Rio de Janeiro, Rio de Janeiro, RJ, 2020.

GREEN, L. J. F. 'Indigenous Knowledge' and 'Science': Reframing the Debate on Knowledge Diversity. Archaeologies, v. 4, n. 1, p. 144-163, abr. 2008.

JARVIS, D. I. et al. An Heuristic Framework for Identifying Multiple Ways of Supporting the Conservation and Use of Traditional Crop Varieties within the Agricultural Production System. Critical Reviews in Plant Sciences, v. 30, n. 1-2, p. 125-176, jan. 2011.

KLOPPENBURG, J. Social Theory and the De/Reconstruction of Agricultural Science: Local Knowledge for an Alternative Agriculture1. Rural Sociology, v. 56, n. 4, p. 519-548, 1991.

LACEY, H. As sementes e o conhecimento que elas incorporam. São Paulo em Perspectiva, v. 14, n. 3, p. 53-59, jul. 2000.

LACEY, H. O princípio de precaução e a autonomia da ciência. Scientiae Studia, v. 4, n. 3, set. 2006. Disponível em: $<$ http://www.scielo.br/scielo.php?script=sci_arttext\&pid=S1678$31662006000300003 \& \operatorname{lng}=\mathrm{pt} \& \mathrm{nrm}=\mathrm{iso} \& \mathrm{t} \operatorname{lng}=\mathrm{pt}>$. Acesso em: 12 nov. 2018.

LACEY, H. Ciência, respeito à natureza e bem-estar humano. Scientiae Studia, v. 6, n. 3, p. 297-324, 2008.

LACEY, H. The life and times of transgenics. In: BENSAUDE-VINCENT, B. et al. (Ed.). Research Objects in their Technological Setting. London: Routledge, 2017. p. 150-165.

LACEY, H.; MARICONDA, P. R. O modelo da interação entre as atividades científicas e os valores na interpretação das práticas científicas contemporâneas. Estudos Avançados, v. 28, n. 82, p. 181-199, dez. 2014.

PERALES, H. R.; BRUSH, S. B.; QUALSET, C. O. Dynamic Management of Maize Landraces in Central Mexico. Economic Botany, v. 57, n. 1, p. 21-34, 2003.

SANTOS, B. de S. Para uma sociologia das ausências e uma sociologia das emergências. Revista Crítica de Ciências Sociais, n. 63, p. 237-280, 2002. 
SANTOS, B. de S. Para além do pensamento abissal: das linhas globais a uma ecologia de saberes. Novos Estudos - CEBRAP, n. 79, p. 71-94, nov. 2007. 